\title{
Groundwater Eco-Distribution System for the Combination of SAT and Therapy-electrolysis Methods
}

\author{
Sabariah Musa ${ }^{1}$, Rafidah Hamdan², Noor Aliza Ahmad', \\ Muhammad Mujiduddin Ibrahim ${ }^{1}$, Fatinah Denan ${ }^{1}$ and Nor Azliana Ariff ${ }^{1}$ \\ ${ }^{1}$ Faculty of Civil and Environmental Engineering, Universiti Tun Hussien Onn Malaysia, Johor, \\ Malaysia \\ ${ }^{2}$ Faculty of Engineering Technology, Universiti Tun Hussien Onn Malaysia, Johor, Malaysia \\ *Corresponding author: sabawater@gmail.com
}

Keywords: Groundwater treatment, activated carbon, clay layer, therapy-electrolysis techniques

\begin{abstract}
Groundwater quality is generally affected by the soil type and being polluted naturally due to the soil properties itself. This paper aims to examine the effectiveness of reducing the contamination of groundwater by a simple treatment using duo soil aquifer treatment (SAT) and therapy-electrolysis processes. The SAT was applied using physical recharge well system (REWES) in deep clay medium. The filtration in the well was also properly designed to purify the abstraction and treat discharges. Other contaminations such as fluoride, nitrate, chloride and turbidity in the groundwater were treated by therapy-electrolysis techniques. This treatment method reduces more than $64 \%$ of contaminations contain without affecting its mineralogy. Therefore, these duo treatments have the best combination of methods to reduce the unneeded contaminations without affecting the groundwater purity. A groundwater eco-distribution system is useful to be implemented in terms of economic process and is ecological friendly for water distribution facilities.
\end{abstract}

\section{Introduction}

The Research Centre for Soft Soil Malaysia (RECESS) has recharge well system (REWES) [1] that is located $1 \mathrm{~km}$ from the nearest factory. Thus, the contamination from it does not affect the groundwater [2]. Unfortunately, the soil condition that has high contains of fluoride, nitrate, and chloride with acidic $(\mathrm{pH})$ and low dissolved oxygen (DO) affects the groundwater quality. The organic contains at the soil also affect the turbidity value of the groundwater. A study [3] stated that raw groundwater quality at RECESS area has contains of fluoride $(8.3 \mathrm{mg} / \mathrm{l})$, nitrate $(12.3 \mathrm{mg} / \mathrm{l})$, chloride (1782 mg/l), turbidity (43NTU) and $\mathrm{pH}(6.4)$. For example, the fluoride material that is more than $2 \mathrm{mg} / \mathrm{l}$ in the groundwater will be considered as contaminated [4].

This study aims to identify the effectiveness of the combination of soil aquifer treatment (SAT) and therapy-electrolysis to remove fluoride, nitrate, chloride and turbidity parameters and to determine optimum length of percentage electrode to stabilize $\mathrm{pH}$ and dissolved oxygen values. This experimental study was set up by using the therapy-electrolysis to groundwater samples which were taken from well (SAT and REWES model) [1].

Therapy-electrolysis was conducted to groundwater samples. The water molecules that have received therapy are more organized and this has accelerated the process of electrolysis treatments. The process was occurs flocculation to surface water and made it easier to eliminate unneeded parameters in the samples. Parameters such as fluoride, nitrate, chloride and turbidity in groundwater samples were composed in charge respectively. At which the positive electrode, negatively charged media from fluoride, nitrate and chloride begin to attract molecules together to produce the larger form as flocculation waste. 
The combination of SAT (REWES model) and therapy-electrolysis treatments also reduces the $\mathrm{pH}$ in groundwater because each alkaline media (fluoride) or acid in water had been removed after the SAT process. In addition, the charge contained in the water can also be neutralized because electrolysis process produces charge to groundwater samples. Each charged molecules will be attracted to their respective electrodes according to the existing charge on the electrode. Therefore, the charge found in the groundwater was more natural.

\section{Materials and Methods}

The materials and methods used are as shown in Figure 1. The samples were divided into two parts which are direct and indirect samples. The direct samples are the samples taken from well (REWES) and tested directly using therapy-electrolysis. The indirect samples are the samples being let to sediment for 3 days before they were treated with the same therapy-electrolysis method. The materials being used for electrolysis are carbon (electrode) and $9 \mathrm{~V}$ battery for the power supply. Figure 2 shows carbon and battery $(9 \mathrm{~V})$ that were used for this study.

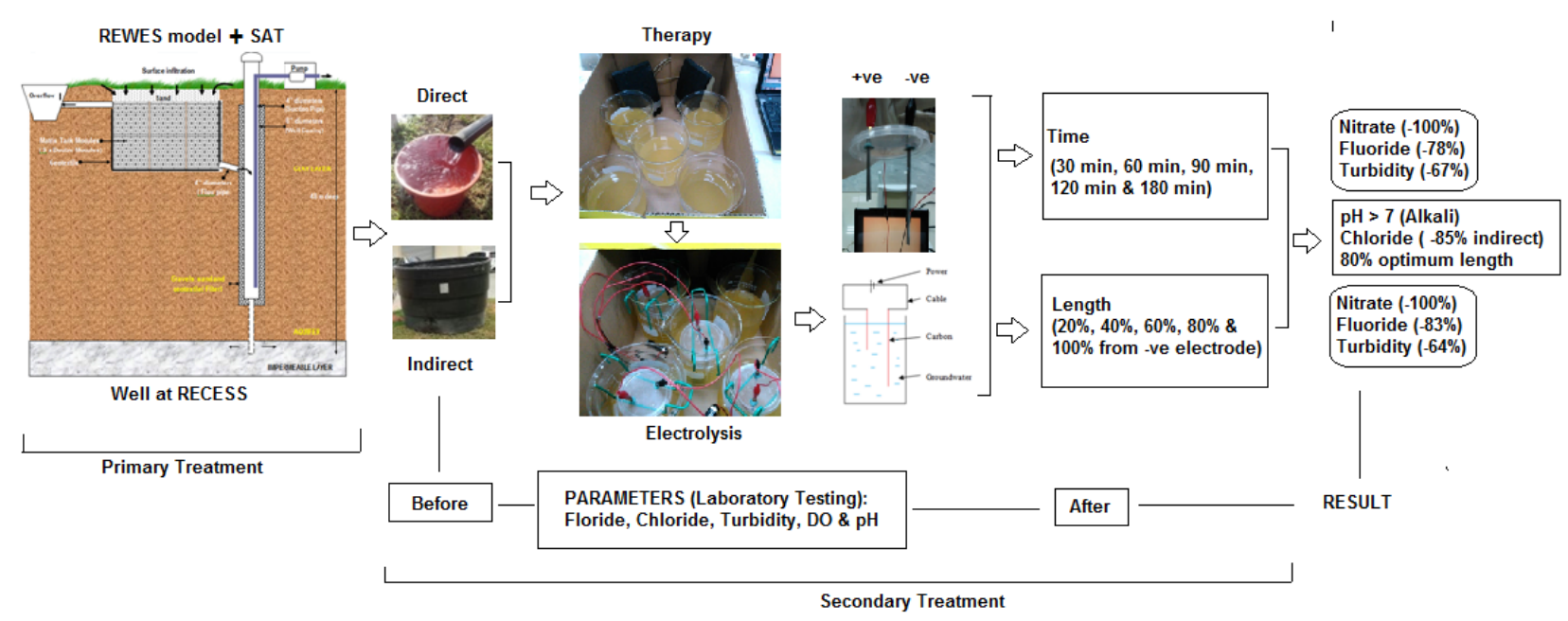

Figure 1: Steps and processes of groundwater for primary and secondary treatments

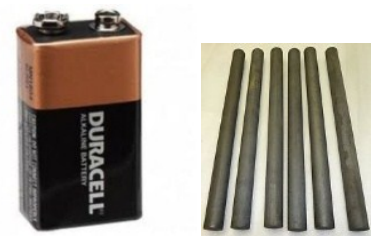

Figure 2: Battery 9 volt (left) and carbon rod (right) used for electrolysis treatment

\section{REWES and SAT (Primary Treatment)}

The REWES was constructed using a real-sized well in Parit Raja, Johor [1]. This is the first groundwater model in Malaysian studies that was designed using a tube of a 150 -mm-diameter well as a recharge well and study case for clay aquifer. Clay aquifer commonly cycled water poorly however, sometimes it can be manipulated by integrating method to over discipline study as soil aquifer treatment (SAT). Groundwater was collected regularly direct and directly sampling by pumping in deep layer until $42 \mathrm{~m}$ deep. 


\section{Therapy-Electrolysis (Secondary Treatment)}

Therapy is a secondary process to rearrange the water molecule by giving Al-Quran reading or any soft sounds. Water has the ability to hear, read and understand human thoughts. According to [5], the water molecule will be more beautiful if given a nice word even simple as word 'thank you'. Then, the secondary treatment was recited to $600 \mathrm{ml}$ of groundwater sample including of Surah Al-Fatihah, Surah Yassin, Surah A-Nas, Surah Al-Ikhlas, Surah Al-Falaq and Surah Al-Khauter for over an hour.

Before the electrolysis treatment, electrolysis was set up according to time and positive electrode length (carbon). By using the carbon, human can control the conductivity value by resizing the area of the carbon. Carbon has a surface that is easy to react to the chemicals and this behavior causes the inclusion of chemical material with carbon if there is a power supply to the cabin [6].

\section{Results and Discussions}

After therapy-electrolysis process was analyzed to groundwater samples in order to determine the water quality reduction of fluoride, chloride, nitrate and turbidity, the results of electrode percentages usage and treatment time are as shown in Figure 3.

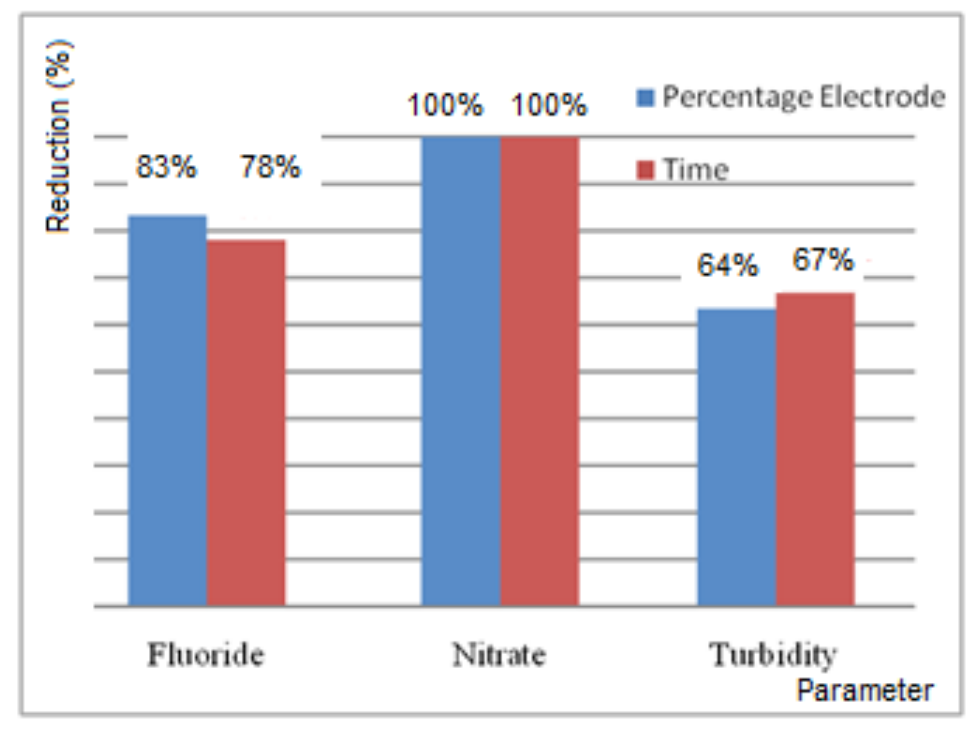

Figure 3: The percentage reduction of fluoride, nitrate and turbidity of groundwater treatment

Results from fluoride, nitrate and turbidity reduction have more effective reactions to treat groundwater quality. This therapy-electrolysis method can decrease the heavy contaminations for more than $64 \%$ for both direct and indirect sampling. This result proved that the combination of time and positive electrode length optimum reduced the amount of fluoride to $83 \%$ (length of electrode) and 78\% (time) respectively. Fluoride is a negative parameter and easily reacts to the positive parameter. The ion value of fluoride is -1 and it is more active compared to chloride because the charge is smaller.

The best result for nitrate clearly decreased from its contaminant to $100 \%$ for both treatments method (length of electrode and time). This reaction showed that nitrate is lighter than fluoride and chloride to dispose from the groundwater. Then, the negative parameter in nitrate reacts positively by contains of nitrogen and trio oxygen.

The turbidity has positive reduce of contaminant around $64 \%$ and $67 \%$ for the length of electrode usage and time treatment respectively. This is shows that the optimum positive electrode for 
reduction of turbidity in the groundwater is less than $80 \%$ because particles movement still occurs during electrolysis process and disturbs the ions particles. Then, the settlement process can increase the fresh and clear water contains.

Electrolysis also purified the groundwater $\mathrm{pH}$ value. Based on these processes, the $\mathrm{pH}$ value of groundwater is to neutral after the treatment although, the raw groundwater is almost neutral and fresh. Then, this therapy-electrolysis process can increase water to become more neutral until $\mathrm{pH} 7.7$ as shown in Figure 4. This process flocculates the acidic water to be more neutral and natural by attracting positive ions from the negative ions.

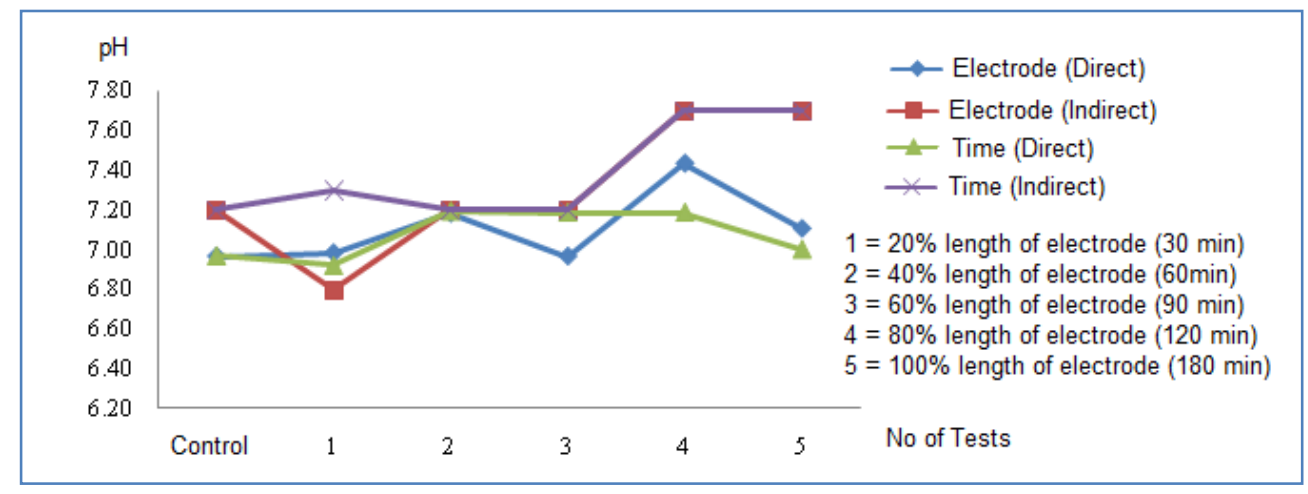

Figure 4: $\mathrm{pH}$ value for both samples analysis

However, no changes were shown in Figure 5 on chloride result because there was no noticeable reduction value of chloride in groundwater through this treatment. However, the chloride indirect treatment can reduce the contaminant to almost $85 \%$ in the process. In the periodic table, the chloride atom is heavier compared to fluoride and nitrate atom. It makes the ionizing process of chloride becomes harder and needs high voltage to make sure it can stick to the electrode thus reducing the value of chloride in the groundwater. Chloride is a negative charge material and is potentially attracted to the positive material. The ion value of chloride is -1 and if there is any positive material nearby, chloride will easily combine and becomes a new material. Thus, in this electrolysis process, the chloride was merged in the end which is positive electrode.

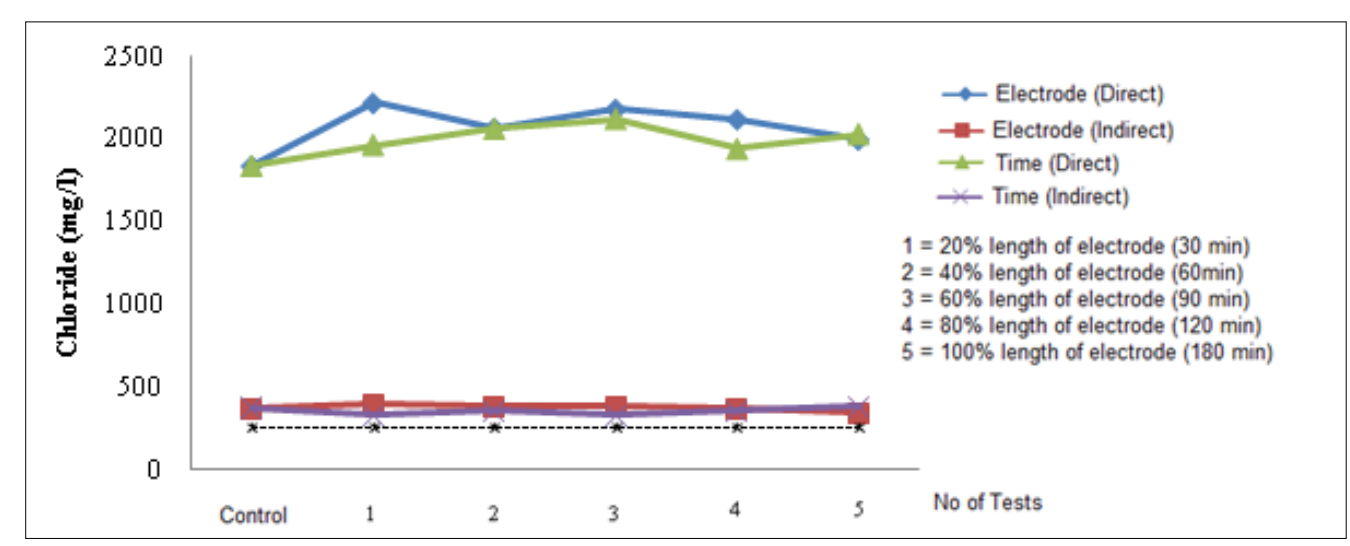

Figure 5: Chloride condition during the treatment process

The treatment also helps to neutralize the groundwater but it does not give effect to the value of dissolved oxygen. Therapy-electrolysis process did not have any effect on the change of dissolved oxygen in the ground water. This is because the positive electrode length is shorter than the length of the negative electrodes in order to attract more positive molecular hydrogen. Therefore, the positive electrode attracts less oxygen content and no significant changes can be seen in the content of dissolved oxygen. 


\section{Conclusion}

The performance of the combination of SAT (using REWES model) and therapy-electrolysis process reduced the percentage of nitrate, fluoride and turbidity effectively. The time showed that the longer time was increased; the percentages of reduction process showed no changes for both chloride and DO parameters. However, the chloride for indirect treatment can reduce the contaminant effectively within time increase in the process. The implication for this study is gave a positive impact to the local people because the integrated groundwater treatment has been found as an alternative water resource that is more economic and user friendly for domestic uses.

\section{Acknowledgment}

Great thanks to Malaysian Ministry of Education for Exploratory Research Grant Scheme (Vot. E039), Universiti Tun Hussein Onn Malaysia and special thanks go to RECESS for kindly providing us location for this project.

\section{References}

[1] Musa, S., Zakaria, N.A., Lai, S.H. and D. Tjahjanto (2010). The Drainage Exchange of Stormwater Potential in Flat Area Problems, Journal of Environmental Science and Engineering, ISSN 1934-8932, Vol. 4 (10) : pp. 1-8.

[2] Musa, S., Zakaria, N. A., Lai, S. H. (2010). Pengekstrakan Air Bawah Tanah Sumber Bekalan Setempat. Persidangan Kebangsaan Hidrologi Alam Sekitar. Batu Pahat, Malaysia: Universiti Tun Hussein Onn Malaysia. 2010. Vol. 8(1): pp. 1-8.

[3] Adnan, A. (2010). Vulnerability Assessment of Deep Groundwater on Quality and Quantity as Alternative Water Supply at RECESS, UTHM Johor. Master Thesis. Universiti Tun Hussien Onn Malaysia.

[4] Groundwater Standard (2010). 15A NCAC 2L.0202.

[5] Gotosi, Y. (2006). Carbon Material. USA : Taylor \& Francis Group.

[6] Emoto, M. (2004). The Journal of Alternative and Complementary Medicine. 10(1): pp. 19-21. 